\title{
Very late onset small intestinal B cell lymphoma associated with primary intestinal lymphangiectasia and diffuse cutaneous warts
}

\author{
Y Bouhnik, I Etienney, J Nemeth, T Thevenot, A Lavergne-Slove, C Matuchansky
}

\begin{abstract}
As only a handful of lymphoma cases have been reported in conjunction with primary intestinal lymphangiectasia, it is not yet clear if this association is merely fortuitous or related to primary intestinal lymphangiectasia induced immune deficiency. We report on two female patients, 50 and 58 years old, who developed small intestinal high grade $B$ cell lymphoma a long time (45 and 40 years, respectively) after the initial clinical manifestations of primary intestinal lymphangiectasia. They presented with a longstanding history of fluctuating protein losing enteropathy, multiple cutaneous plane warts, and markedly dilated mucosal and submucosal lymphatic channels in duodenal biopsies. One had a large ulcerated tumour of the proximal ileum and the other diffuse ileal infiltration. In both, histological examination showed centroblastic high grade B cell lymphoma associated with duodenojejuno-ileal mucosal and submucosal lymphangiectasia. They were subsequently successfully treated with surgery and postoperative chemotherapy (AVmCP: adriamycin, cyclophosphamide, Vm26, and prednisolone), and chemotherapy alone (PACOB: adriamycin, cyclophosphamide, vincristine, bleomycine, and prednisolone), respectively. A three year follow up in both cases showed persistent diffuse lymphangiectasia without evidence of lymphoma. The present findings support the hypothesis that primary intestinal lymphangiectasia is associated with lymphoma development. (Gut 2000;47:296-300)
\end{abstract}

Pathology, Hôpital Lariboisière, Paris,

France

J Nemeth

A Lavergne-Slove

Correspondence to: Dr Y Bouhnik, Hôpital Lariboisière, 2 rue Ambroise Paré, 75475 Paris Cedex 10,

France. Email

yoram.bouhnik@,

lrb.ap-hop-paris.fr

Accepted for publication 1 February 2000 rare disease characterised by abnormally dilated lymphatics in the small intestinal wall and/or the mesentery. It is associated with either a systemic disorder of the lymphatic system ${ }^{1}$ or with a process specifically located in the gastrointestinal tract. ${ }^{2}$ This results in extreme leakage of lymph into the gastrointestinal tract causing loss of proteins, immunoglobulins, and lymphocytes which in turn leads to depression of both the humoral and cellular immune systems. ${ }^{3}$ Given the rare nature of PIL, it is not clear if the occurrence of malignancy, especially lymphoma, is fortuitous or related to PIL induced immune deficiency, as in primary immunodeficiency syndromes. ${ }^{45}$ Indeed, only a handful of PIL related lymphoma cases have been reported ${ }^{4-11}$ : six of these were located in the gastrointestinal tract. We report on two further patients with longstanding PIL who developed very late onset small intestinal B cell lymphoma (several decades after the initial clinical manifestations of protein losing enteropathy).

\section{Case reports}

PATIENT NO 1

A 50 year old woman was admitted in August 1995 for assessment and management of König syndrome and leg oedema. Her past medical records dated back to 1950 when she was five years old and suffered chronic diarrhoea, steatorrhoea, and abdominal distension. In 1956, at the age of 11 , a chylous ascites was discovered in association with severe hypoproteinaemia and lymphopenia. On exploratory laparotomy there was a voluminous, hard, diffuse mesenteric mass containing an opalescent fluid, small amounts of chylous ascites, and an inflammatory appendix; a diagnosis of diffuse lymphangioma was suspected on macroscopic examination but the whole intestinal wall was diffusely thickened, and dilated small intestinal lymphatics extending from the duodenum to the ileum were observed as a fatty meal had been administered 12 hours before surgery. No radical surgical treatment was considered and the patient was managed conservatively. Examination of mesenteric biopsy specimens showed marked dilatation of the lymphatics with fat filled macrophages. PIL was diagnosed; compliance with dietary fat intake and supplementation with medium chain triglycerides was low. The subsequent
Abbreviations used in this paper: PIL, primary intestinal lymphangiectasia; HTLV-1, human T cell lymphotrophic virus type 1 . 
evolution varied; four years later, at the age of 15 , recurrent chylous ascites associated with severe hypoproteinaemia necessitated a second laparotomy. Findings were similar to the previous ones, confirming massive and even aggravated infiltration of the total small intestine and mesentery. But follow up showed that compliance to lipid dietary restrictions had improved: the clinical outcome proved satisfactory, except for short episodes of leg oedema and cutaneous plane warts. Growth and puberty proved normal; at the age of 25 a first pregnancy was uneventful.

On August 1995-that is, 45 years after the initial clinical manifestations of protein losing enteropathy and 39 years after the first diagnosis of PIL - the patient was admitted to our hospital with abdominal pain. Physical examination showed oedema of the legs and multiple warts on the dorsal of her hands, forearms, back, and legs. There was no abdominal mass, ascites, lymphadenopathy, or hepatosplenomegaly. Her weight was $63 \mathrm{~kg}$ and height $161 \mathrm{~cm}$. The family history was not contributory. Erythrocyte and blood cell counts were normal except for lymphopenia (400-600 per $\mu \mathrm{l})$. Peripheral CD 4 cell count was low (57 per $\mu \mathrm{l})$, as were the CD8 count (342 per $\mu \mathrm{l})$ and $\mathrm{CD} 4 / \mathrm{CD} 8$ ratio. There was severe hypoproteinaemia (42 g/l) and hypoalbuminaemia (24 $\mathrm{g} / \mathrm{l})$, and markedly decreased levels of immunoglobulins, mainly IgG $(2.2 \mathrm{~g} / 1$; normal $>6.9$ $\mathrm{g} / \mathrm{l})$, and also $\operatorname{IgA}(0.38 \mathrm{~g} / \mathrm{l}$; normal $>0.8 \mathrm{~g} / \mathrm{l})$ and $\operatorname{IgM}(0.2 \mathrm{~g} / 1$; normal $>0.4 \mathrm{~g} / \mathrm{l})$ classes. There was no proteinuria on repeated examination. Liver and renal function proved normal. Serological tests for human immunodeficiency virus type 1 and 2 and for human T cell lymphotrophic virus type 1 (HTLV-1) proved negative.

Upper gastrointestinal endoscopy showed multiple whitish pseudo polyps, suggesting lymphangiectasia, extending from the proximal duodenum to Treitz's ligament. Ileocolonoscopy proved normal. Duodeno-jejunal and ileal biopsies showed markedly dilated mucosal and submucosal lymphatic channels, with polyclonal normal plasma cells. An $x$ ray of the small bowel follow through showed an ulcerated stenosis of the proximal ileum located approximately $200 \mathrm{~cm}$ beyond Treitz's ligament. Computerised abdominal tomography showed a tumour-like thickened proximal ileum with no evidence of mesenteric lymphadenopathy. An $x$ ray and CT scan of the chest were normal, as were hepatic and medullar biopsies.

At laparotomy, a large ulcerated small intestinal tumour $(90 \times 45 \mathrm{~mm})$ located in the proximal ileum was found but there was no evidence of mesenteric or hepatic metastases. The whole tumour was removed with macroscopically healthy small intestinal margins. The specimens were fixed in $10 \%$ formalin. Histological examination revealed numerous diffuse lymphangiectasias in the mucosa and submucosa (fig 1). The tumour was ulcerated and associated with the whole intestinal wall. It consisted of diffuse proliferation of typical large centroblastic lymphoid cells with one or two nucleoli (fig 2). In paraffin embedded sections,

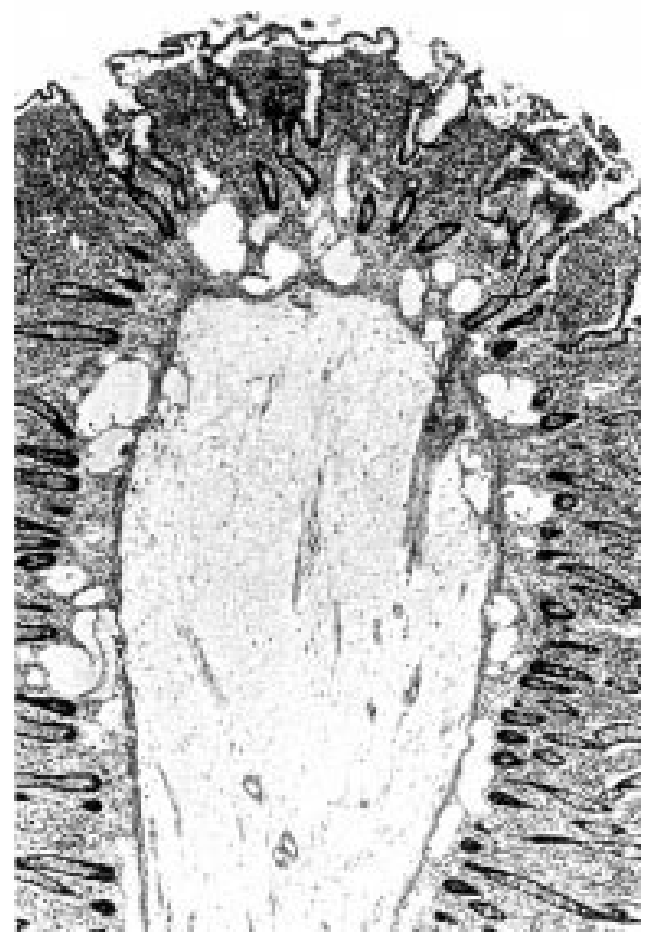

Figure 1 Patient No 1. Ileal resection piece: note the numerous lymphangiectasias in the mucosa and submucosa (haematein-erythrosin, $G \times 100$ ).

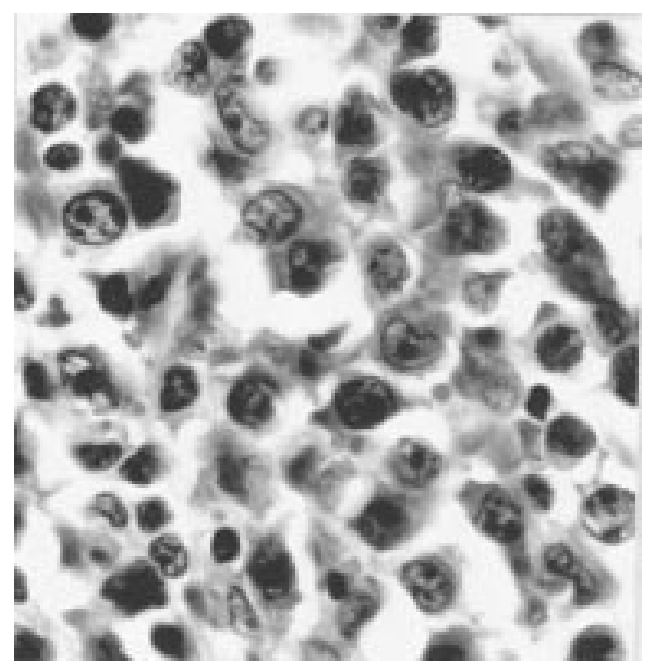

Figure 2 Patient No 1. Ileal resection piece: tumour cells are large lymphoid cells with one or two nucleoli (haematein-erythrosin, $G \times 3000$ ).

the tumour cells were diffusely positive for CD45 and CD20 (L26) and negative for CD3; no immunoglobulins were detected. There was neither a low grade component nor lymphoepithelial lesion. Plasma cells were normal. A diagnosis of centroblastic high grade B cell lymphoma, according to the Kiel classification, was made. In situ hybridisation and polymerase chain reaction for HTLV-1 and Epstein-Barr virus on intestinal tissue proved negative.

Postoperatively, four, 5-day cycles of chemotherapy using AVmCP (adriamycin $80 \mathrm{mg}$ intravenously on day 1 , cyclophosphamide $1 \mathrm{~g}$ intravenously on day 1, Vm26 $100 \mathrm{mg}$ intravenously on day 1 , and prednisolone $100 \mathrm{mg}$ /day orally for five days) were delivered. There were 
no serum anti-IgA antibodies and the patient received polyvalent immunoglobulins intravenously at three week intervals.

In 1996, 1997, and 1998, duodenal perendoscopic biopsies showed persistent lymphatic channel dilatations with normal plasma cell density, with no evidence of lymphoma. Computerised abdominal tomography proved normal. Serum albumin was $27 \mathrm{~g} / 1$ with decreased levels of $\operatorname{IgG}(3.35 \mathrm{~g} / \mathrm{l}), \operatorname{IgA}(0.38 \mathrm{~g} / \mathrm{l})$, and $\operatorname{IgM}$ $(0.25 \mathrm{~g} / \mathrm{l})$. Polyvalent immunoglobulins were administered monthly for three years. To date, the patient has remained well except for episodes of leg oedema but with no evidence of lymphoma relapse.

PATIENT NO 2

A 58 year old woman was admitted in 1996 for evaluation of severe hypoalbuminaemia as a result of protein losing enteropathy. She had complained of leg oedema for 40 years since the age of 18, of diarrhoea for seven years, and of abdominal pain for several months. Her past medical history included post partum phlebitis at the age of 25, bilateral pleural effusion, chronic bronchitis, and arterial hypertension. On admission, physical examination showed symmetric leg oedema, moderate right pleural effusion, and plane warts on the back of the fingers and hands. There was an abdominal mass, ascites, lymphadenopathy, and hepatosplenomegaly. The familial history was not contributory.

Laboratory investigations showed severe hypoalbuminaemia (20 g/1), normal leucocyte counts, but lymphopenia (500-700 per $\mu \mathrm{l})$. Peripheral $\mathrm{T}$ cell counts showed 748 natural killers, $88 \mathrm{CD} 4$, and $132 \mathrm{CD} 8$ lymphocytes per $\mu \mathrm{l}$, with a decreased $\mathrm{CD} 4 / \mathrm{CD} 8$ ratio $(0.67$; normal $>1$ ). Liver and renal function tests were normal. There was no proteinuria. An $x$ ray of the small bowel follow through showed a diffusely thickened ileal wall with small nodular lesions, and abdominal CT scan showed a diffusely thickened small intestinal wall. Upper enteroscopy and ileocolonoscopy showed multiple whitish pseudo polyps, suggesting lymphangiectasia, involving the duodenum, the upper $50 \mathrm{~cm}$ of the jejunum, and the lower $80 \mathrm{~cm}$ of the ileum.

On duodenojejunal and ileal perendoscopic biopsies, diffusely dilated mucosal and submucosal lymphatic channels were observed (fig 3). Ileal specimens also showed diffuse proliferation of large lymphoid cells of the centroblastic type, with round nuclei and one or two nucleoli. They were mixed with normal small round lymphoid cells. There were no lymphoepithelial lesions. Immunohistochemical analysis of paraffin embedded specimens revealed that the large lymphoid cells were CD20, whereas the small lymphoid cells were CD3 + T cells of the reactive type. Plasma cells were normal. Most expressed IgA, with two thirds for the $\kappa$ chain and one third for the $\lambda$ chain. A diagnosis of centroblastic high grade B cell lymphoma was made, according to the Kiel classification.

Osteomedullary biopsy and CT scans of the chest and cavum proved normal. Abdominal

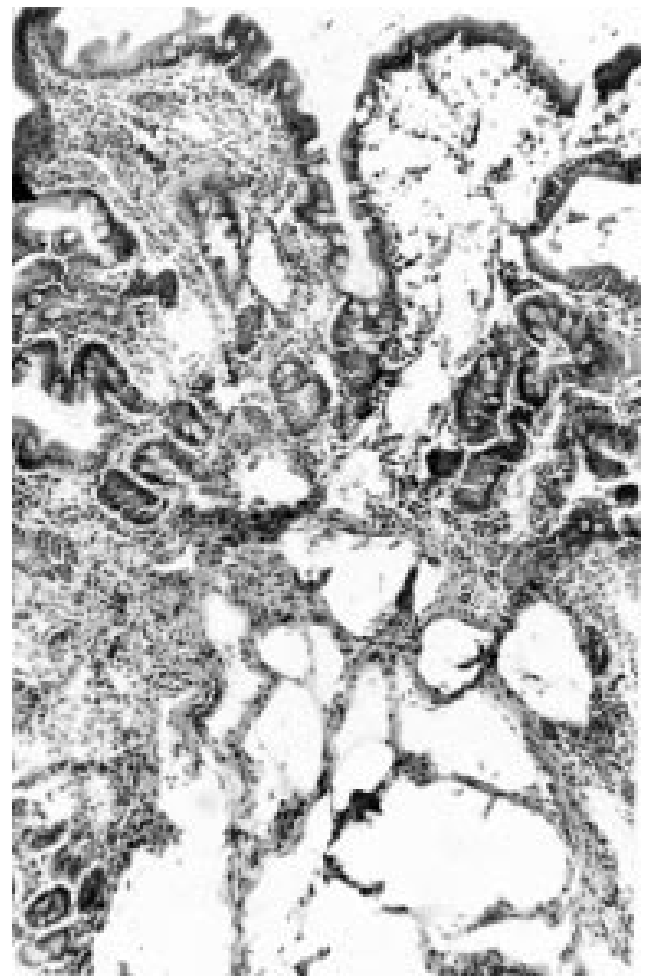

Figure 3 Patient No 2. Perendoscopic jejunal biopsy (frozen sample): numerous mucosal and submucosal lymphangiectasias (haematein-erythrosin, $G \times 300$ ).

CT scan revealed no evidence of mesenteric or hepatic metastases. Three, 3-week cycles of chemotherapy using PACOB (adriamycin 50 mg on days 1-5, cyclophosphamide $600 \mathrm{mg}$ on days $1-15$, vincristine $2 \mathrm{mg}$ on days $8-22$, bleomycin $8 \mathrm{mg}$ on days 8-22, and prednisolone $60 \mathrm{mg}$ on days $1-5$ and 15-19) were delivered.

At control ileocolonoscopy in September 1996 there was no evidence of lymphoma but persistent lymphatic dilatations on duodenal and ileal biopsy specimens were noted. To date, the patient has remained in a satisfactory clinical condition, except for bilateral leg oedema and hypoalbuminaemia, with no evidence of lymphoma.

\section{Discussion}

In our two patients, small intestinal high grade B cell lymphoma was diagnosed 45 and 40 years after the initial clinical manifestations of protein losing enteropathy caused by PIL. A diagnosis of PIL was clearly suggested by several observations: (a) early onset, in childhood and adolescence, respectively, of symptoms directly related to protein losing enteropathy - that is, peripheral hypoalbuminaemic oedema (due to intestinal lymph loss), chylous peritoneal, and pleural effusions ${ }^{12}$ - or to marked depression of cell mediated immunity (longstanding cutaneous warts of presumably viral origin). Indeed, such cutaneous viral warts have already been reported as a clinical presentation of PIL $^{6}{ }^{11}$; (b) anatomical demonstration in patient No 1 of enteromesenteric (pseudo lymphangiomatous) lymphangiectasia at the age of 11 - that is, nearly 40 years before 


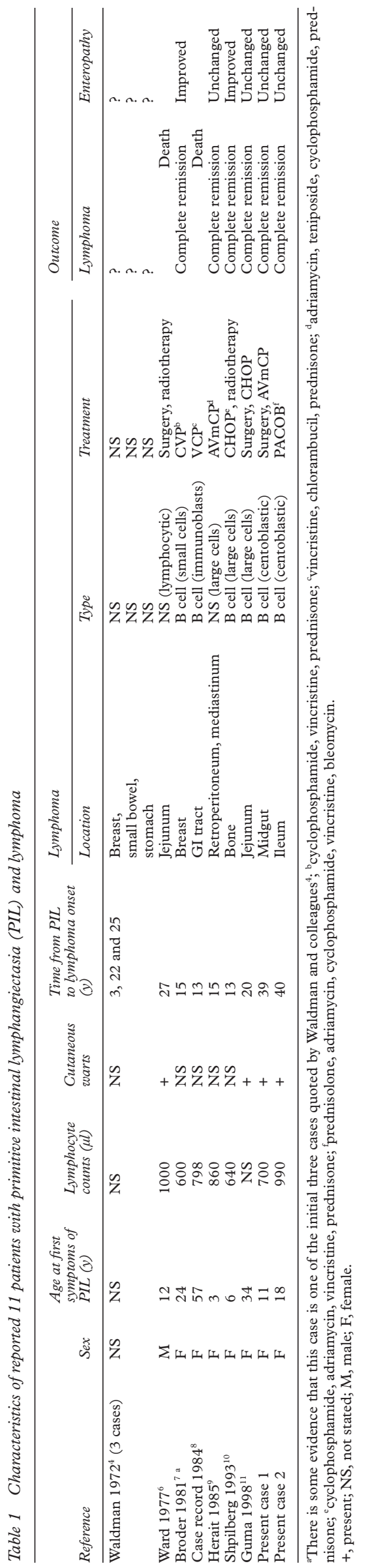

the onset of lymphoma; and (c) persistent small intestinal diffuse lymphangiectasia in both patients after successful treatment of the lymphoma.

The association of primitive gastrointestinal protein loss with systemic lymphatic abnormalities has led to the suggestion that PIL may be part of a congenital disorder of the lymphatic system as a whole. ${ }^{13}$ But there is now evidence that the clinical spectrum of PIL is proving more protean than had been suspected originally, and that in addition to cases of systemic lymphatic abnormalities, primary lymphangiectasia confined to the intestine does exist. $^{2}$ None of our patients showed clinical evidence of peripheral lymphatic abnormalities (for example, asymmetric peripheral lymphoedema of the limbs) while both had recurrent symmetrical leg oedema caused by hypoalbuminaemia per se. Spontaneous fluctuations in the clinical severity of PIL, as observed in our patients and probably accounting for prolonged high clinical tolerance, have been reported previously. ${ }^{212}$

To our knowledge, supervening lymphoma has been reported in only nine patients with PIL, 3-27 years after the clinical onset of PIL manifestations. A further patient who developed B cell lymphoblastic leukaemia has been reported. ${ }^{5}$ The characteristics of these patients are summarised in table 1 .

Rather than being merely fortuitous, lymphoma may well be related to intestinal lymphangiectasia as a consequence of several mechanisms: (a) lymphoma may cause secondary intestinal lymphangiectasia by means of lymphatic channel blockade, an unlikely hypothesis in our patients for whom anatomical and/or clinical evidence of diffuse duodenojejuno-ileal PIL preceded the onset of lymphoma by several decades; (b) longstanding protein losing enteropathy may be resolved after combining chemotherapy and/or irradiation, as previously reported in two patients with lymphoma ${ }^{70}$ : in one, evidence was provided of the disappearance of lymphatic abnormalities on per oral duodenal biopsies five years after the end of lymphoma treatment. The hypothesis has been raised of an as yet undefined inflammatory process in these patients causing impairment of lymphatic flow which may have been coincidentally cured by a combination of chemotherapy, irradiation, and/or steroids ${ }^{14}$; (c) much more likely is the fact that lymphoma in PIL patients could well be related to immune deficiency. Several arguments support this. Firstly, the lag time between the onset of PIL and lymphoma may be very long, as in patients with primary immune deficiency and lymphoma ${ }^{4}$; in our patients, this lag time was more than four decades, to our knowledge the longest time reported. Secondly, a primary deficiency of B cell and/or helper $\mathrm{T}$ cell function has been suggested in PIL ${ }^{15}$ in association with the secondary immune deficiency induced by loss of immunoglobulins and lymphocytes ${ }^{16}{ }^{17}$; this hypothesis is supported by the reported persistence of immune disorders even after normalisation of Ig levels and proteinaemia with dietary treatment ${ }^{18} 19$ and by 
the presentation of multiple viral warts in our patients as in two other patients with lymphoma and PIL. ${ }^{11}$ However, unlike patients with primary immunodeficiency syndromes, PIL patients do not exhibit clear evidence of depressed intestinal immunity: plasma cell number in duodenojejunal lamina propria was normal in both of our patients as in most of those reported previously. This finding is in accordance with the absence of an association in PIL of overt gut infection such as giardiasis compared with primary immune deficiency patients. ${ }^{2021}$

Continuous loss of $\mathrm{T}$ cells and immunoglobulins into the gut may indeed be the decisive event in the onset of intestinal lymphoma in PIL. The role of Epstein-Barr virus $^{22}$ and HTLV-1 infection cannot be considered for our patients (in particular for patient No 1 in whom it was sought), as in the single published case in which evidence for these infections was sought. ${ }^{9}$ Finally, the precise pathogenesis of lymphoma in these immunodepressed PIL patients has yet to be established. It may imply a defect in immunosurveillance, more specifically impairment in early detection and destruction of neoplastic cells which give rise to the lymphoma, ${ }^{23}$ or increased loss of suppresser $\mathrm{T}$ cells having favoured growth of an autonomous B cell clone. ${ }^{24}$ Cases of Waldenström's disease have been reported in association with acquired intestinal lymphangiectasia in the elderly but no significant correlation between such a secondary protein losing enteropathy and the occurrence of lymphoma has been reported; the rather shorter duration of protein losing enteropathy induced immunodeficiency in these patients may be an explanation. ${ }^{25}$

In conclusion, our two cases of high grade B cell lymphoma associated with PIL support the hypothesis that PIL predisposes to lymphoma.

1 Pomerantz M, Waldmann TA. Systemic lymphatic abnormalities associated with gastrointestinal protein loss secondary to intestinal lymphangiectasia. Gastroenterology 1963;45:703-11

2 Vardy PA, Lebenthal E, Shwachman H. Intestinal lymphangiectasia: a reappraisal. Pediatrics 1975;55:842-51.

3 Brasitus TA, Bissonnette M. Protein-losing enteropathy. In: Sleisenger MH, Fordtran JS, eds. Gastrointestinal and liver diseases: pathophysiology, diagnosis and management, 6th edn. Philadelphia: WB Saunders, 1998: 369-75.
4 Waldmann TA, Strober W, Blaese RM. Immunodeficiency disease and malignancy. Ann Intern Med 1972;77:605-28. 5 Kay AJ, Lilleyman JS. Is intestinal lymphangiectasia a pre-leukaemic condition? Clin Lab Haematol 1981;3:3657.

6 Ward M, Le Roux A, Small WP, et al. Malignant lymphoma and extensive viral wart formation in a patient with intestinal lymphangiectasia and lymphocyte depletion. Postgrad Med f 1977;53:753-7.

7 Broder S, Callihan TR, Jaffe ES, et al. Resolution of long-standing protein-losing enteropathy in a patient with intestinal lymphangiectasia after treatment for malignant lymphoma. Gastroenterology 1981;80:166-8.

8 Case records of the Massachusetts General Hospital. N Engl f Med 1984;310:512-20.

9 Herait P, Gisselbrecht C, Ferme C, et al. Lymphome non hodgkinien survenant au cours d'une lymphangiectasie intestinale de Waldmann. Nouv Rev Fr Hematol 1985;27: 299-302.

10 Shpilberg O, Shimon I, Bujanover Y, et al. Remission of malabsorption in congenital intestinal lymphangiectasia following chemotherapy for lymphoma. Leuk Lymphoma 1993;11:147-8.

11 Guma J, Rubio J, Masip C, et al. Aggressive bowel lymphoma in a patient with intestinal lymphangiectasia and widespread viral warts. Ann Oncol 1998;9:1355-6.

12 Waldmann TA, Steinfeld JL, Dutcher TF, et al. The role of the gastrointestinal system in "idiopathic hypoproteinemia”. Gastroenterology 1961;41:197-207.

13 Jeffries GH. Protein losing gastroenteropathy. In: Sleisenger $\mathrm{MH}$, Fordtran JS, eds. Gastrointestinal diseases: pathophysiology, diagnosis and management. Philadelphia: WB Saunders, 1989:283-90.

14 Fleisher TA, Strober W, Muchmore AV, et al. Corticosteroid-responsive intestinal lymphangiectasia secondary to inflammatory process. $N$ Engl f Med 1979;300: 605-6.

15 Heresbach D, Raoul JL, Genetet N, et al. Immunological study in primary intestinal lymphangiectasia. Digestion 1994;55:59-64

16 Weiden PL, Blaese RM, Strober W, et al. Impaired lymphocyte transformation in intestinal lymphangiectasia: evidence for at least two functionally distinct lymphocyte populations in man. F Clin Invest 1972;51:1319-25.

17 Myszor MF, Davidson A, Hodgson HJF. The local mucosal immune system in intestinal lymphangiectasia. 7 Clin Lab Immunol 1988;26:1-3.

18 Yamamoto $\mathrm{H}$, Tsutsui $\mathrm{T}$, Mayumi $\mathrm{M}$, et al. Immunodeficiency associated with selective loss of helper/inducer T cells and hypogammaglobulinaemia in a child with intestinal lymphangiectasia. Clin Exp Immunol 1989;75:196-200.

19 Tift WL, Lloyd JK. Intestinal lymphangiectasia: long term results with MCT diet. Arch Dis Child 1975;50:269-75.

20 Gatti RA, Good RA. Occurrence of malignancy in immunodeficiency diseases. A literature review. Cancer 1971;28:8998.

21 Kinlen LJ, Webster AD, Bird AG, et al. Prospective study of cancer in patients with hypogammaglobulinaemia. Lancet $1985 ; 2: 263-6$

22 Larvol L, Soulé JC, Le Tourneau A. Reversible lymphoma in the setting of azathioprine therapy for Crohn's disease. $N$ Engl F Med 1994;331:883-4.

23 Burnet FM. The concept of immunological surveillance. Prog Exp Tumour Res 1970;13:1-27.

24 Strober W, Wochner RD, Carbone PP, et al. Intestinal lymphangiectasia: a protein-losing enteropathy with hypogammaglobulinemia, lymphocytopenia and impaired homograft rejection. $\mathcal{F}$ Clin Invest 1967;46:1643-56.

25 Harris M, Burton IE, Scarffe JH. Macroglobulinaemia and intestinal lymphangiectasia: a rare association. $\mathcal{F}$ Clin Pathol 1983;36:30-6. 